\title{
Nature: A New Paradigm for Well-being and Ergonomics
}

Miles Richardson, Marta Maspero, David Golightly*, David Sheffield, Vicki Staples and Ryan Lumber.

University of Derby, Kedleston Road, Derby, DE22 1GB, UK.

*University of Nottingham, University Park, Nottingham, NG7 2RD, UK.

Corresponding Author: Dr Miles Richardson, m.richardson@ derby.ac.uk, +44 1332593056.

Published version: Richardson, M., Maspero, M., Golightly, D., Sheffield, D., Staples, V., \& Lumber, R. (2016). Nature: a new paradigm for well-being and ergonomics.Ergonomics, 1-14. 


\title{
Nature: A New Paradigm for Well-being and Ergonomics
}

\author{
Nature is presented as a new paradigm for ergonomics. As a discipline concerned with \\ well-being the importance of natural environments for wellness should be part of \\ ergonomics knowledge and practise. This position is supported by providing a concise \\ summary of the evidence of the value of the natural environment to well-being. \\ Further, an emerging body of research has found relationships between well-being and \\ a connection to nature, a concept that reveals the integrative character of human \\ experience which can inform wider practice and epistemology in ergonomics. \\ Practitioners are encouraged to bring nature into the workplace, so that ergonomics \\ keeps pace with the move to nature-based solutions, but also as a necessity in the \\ current ecological and social context.
}

Keywords: Nature, health, well-being, ergonomics.

Practitioner Summary: Nature-based solutions are coming to the fore to address societal challenges such as well-being. As ergonomics is concerned with well-being there is a need for a paradigm shift in the discipline. This position is supported by providing a concise summary of the evidence of the value of the natural environment to well-being. 


\section{Introduction}

Ergonomics is concerned with well-being. The second of the two objects of the royal charter of the Chartered Institute of Ergonomics and Human Factors (CIEHF) refers to the promotion of well-being through the use of ergonomics knowledge (CIEHF 2014). This paper argues that the ergonomics knowledge base should include the benefits of nature for human wellbeing. The health benefits of nature outlined in the present review provide that knowledge and show that nature provides a new paradigm for well-being (European Commission 2015; Stevens 2010), in contrast to the existing biomedical model of healthcare that essentially views people as separate from the environment and affected by events, with deviation from normal being treated with costly interventions. Upstream nature-based solutions that harness the power of nature to turn challenges into opportunities are coming to the fore to address societal challenges such as well-being (European Commission 2015). As the EU research and policy agenda recognises the human need for nature, disciplines such as ergonomics will also have to transform the solutions they offer, bringing nature into the workplace to address major challenges such as work related stress and ill-health (WHO 2011). At present, workplace health programmes tend not consider nature (Lottrup, Grahn and Stigsdotter 2012; Trau, Keenan, Goforth, and Large 2015), despite the health benefits of nature being known for many years (Logan and Selhub 2012; Nisbet, Zelenski, and Murphy 2011). This mirrors, and is perhaps caused by, the wider societal dissociation from nature in an age of rapid global urbanisation (Barnosky at al. 2011; Maller et al. 2009), bringing about increases in mental health issues (Walsh 2011) and lifestyle diseases (Pappachan 2011). This should be noted by ergonomics practitioners, as reduced performance at work and long-term sickness absence are related to mental health issues (Sahlin, Ahlborg, Matuszczyk and Grahn 2014).

Nature does much more than provide a route to workplace wellness; it provides a new paradigm for ergonomics informing epistemology of the discipline (the second object of the 
CHIEF royal charter) and wider practice through revealing the integrative character of human experience. The continued loss of biodiversity (EEA 2015) and the links to human well-being (von Hertzen et al. 2015) has brought the concept of connection to nature and reconnecting people with nature to the fore (DEFRA 2011). The concept has been the focus of many high profile campaigns recently (e.g. Wild Network 2015), including ones that focus on the workplace (e.g. 30x30 at Work, David Suzuki Foundation 2015). Rather than simple exposure to nature, there is emerging evidence that an affinity or connection to nature is good for well-being to a level similar to established variables such as income and education (Capaldi, Dopko and Zelenski 2014). The construct of nature connectedness is seeing one's self as part of a wider ecology and has a positive impact on valuable workplace factors such as vitality, creativity and happiness (Capaldi et al. 2014), while also leading to other benefits such as pro-social behaviour and pro-environmental behaviour (e.g. Frantz and Mayer 2014, Zhang, Piff, Iyer, Koleva and Keltner 2014). This concept of a shared place in nature ties into integrative perspectives on ergonomics, and the indivisibility of cognition and environment (Flach et al., 2008; Dekker et al. 2013).

In order to support the case that nature provides a new paradigm for ergonomics, the beneficial impact of nature is reviewed to indicate how nature can help deal with workplace well-being, with well-being defined in the review as encompassing variables such as life satisfaction, vitality and mood (Cervinka et al. 2012). To support this need and impact on decision-making, the present review provides a concise summary and armoury of the evidence of the benefits of nature to well-being while highlighting the emerging importance of connectedness to nature. In addition to bringing the benefits of well-being and innovation into the workplace, Ergonomics and Human Factors practitioners can, at the same time, contribute to the revival of nature through their efforts (c.f. Hanson 2013). As well as bringing nature into the workplace for its benefits to humans, there is an opportunity, indeed 
a necessity, to understand and promote a connection to nature so that benefits to both humans and the natural world can be realised in order to deliver a sustainable future. The research presented below focuses on everyday exposure to nearby nature (Kaplan and Kaplan 1989); the nature accessible on our journeys to work, in our lunch breaks or even viewable through the window (Author, 2015). It is this everyday nature that will increasingly become where we engage with nature in a progressively urbanised world (Dunn et al. 2006), although it should be noted that there is emerging evidence of links between biodiversity and well-being (e.g. von Hertzen et al. 2015). Papers were selected based on the themes of nature, health, well-being and restoration in order to provide a selection of peer-reviewed studies indicative of the area from broadly relevant populations. The selected papers were then tabulated to indicate key characteristics such as measures used and design in order to provide an accessible overview. In order to evidence nature as a new paradigm for well-being and ergonomics, the current paper opens by presenting the body of empirical research examining the benefits of exposure to nature and then the concept of a connection to nature is introduced. Next, the theories regarding the human need for nature are briefly introduced. The wider implications of the concept of nature connectedness for a paradigm shift in ergonomics are then considered.

\section{Beneficial Effects of Nature}

The following sections introduce the evidence for the role of nature in well-being. Starting with general health it goes on to examine subjective well-being and restoration, providing an evidence base for the ergonomist promoting provision and access to nature in the workplace in order to improve well-being, and ultimately absenteeism and productivity. Going beyond everyday exposure to nature, to activity in nature, there is evidence that 'nature experience', including wilderness experiences, have benefits for health and well-being (e.g. Hartig et al 
1991). This is not reviewed here but has been comprehensively discussed within a theoretical context by Hartig et al. (2011).

\subsection{General Health Benefits}

A cluster of studies investigating the link between nature and health have focused on the health gap between people living in rural and urban locations, providing underlying support to bringing nature to the workplace. Studies in many countries have shown that urban people are more likely to report a poorer health status than their rural counterparts (Verheij, van de Mheen, de Bakker, Groenewegen, and Mackenbach 1998; Weich, Twigg, and Lewis 2006). However, recent epidemiological studies have demonstrated that the association between people's perceived health and the availability of green spaces is stronger than the one between health and urbanicity (de Vries, Verheji, Groenewegen, and Spreeuwenberg 2003; Maas, Verheij, Groenewegen, de Vries, and Spreeuwenberg 2006; Verheij et al. 2008). These findings suggest that the urban-rural health gap is not fully accounted for by differences in environmental factors and unhealthy behaviours and is instead mediated by an actual discrepancy in nature availability.

Several other studies add to the growing evidence of the major health benefits provided by the natural environment, which can feed into workplace design and work routine options. For example, a study by Agyemang et al. (2007) established a relationship between the presence and the quality of green spaces in the neighbourhood and lower hypertension rates among residents. Donovan et al. (2013) found evidence to suggest that areas subjected to a loss of trees owing to disease had increased mortality due to lower-respiratory-tract and cardiovascular illnesses. Further, in a study by Raanaas et al. (2012), patients of a residential rehabilitation programme self-reported a better physical and mental health if their bedroom had a view of natural surroundings. Finally, green buildings have higher light levels, greater access to windows, conditions associated with thermal comfort, and fewer airborne 
particulates with occupants reporting a lower frequency of visual and physical discomfort symptoms, better mood, and better sleep quality (Newsham et al. 2013). Green spaces have also been argued to facilitate exercise and social contact (Van den Berg, Hartig, and Staats 2007) and a study by Van den Berg, Maas, Verheij, and Groenewegen (2010) has shown that the amount of nearby green areas moderates the relationship between stress and health, thus suggesting that nature might help preserve health by acting as a buffer against stress. As indicated by the summary presented in Table 1, generic guidelines for work can be derived from such research, namely the availability of, and access to, green space with trees.

Insert Table 1 about here

\subsection{Well-being Benefits}

A positive association between nature and subjective well-being has also been established, see Table 2. Well-being is a complex construct for which several definitions exist (McMahan and Estes 2011). In this context, it has a wide-ranging meaning, encompassing variables such as mood, life satisfaction, psychological well-being, and vitality (Cervinka et al. 2012). Availability of green spaces in nearby areas (Gidlof-Gunnarsson and Ohrstrom 2007; Groenewegen, van den Berg, de Vries, and Verheij 2006), natural views from windows (Kaplan 2001; Ulrich 1979), and time spent in nature (Lafortezza, Carrus, Sanesi, and Davies 2009; Pretty et al. 2007) have all been demonstrated to increase well-being, including job satisfaction (Leather, Pyrgas, Beale and Lawrence 1998). Furthermore, exposure to nature, both physically and visually, has been shown to have a positive effect on mental health (Guite, Clark, and Ackrill 2006; Ottosson and Grahn 2008), vitality (Guite et al. 2006), mood (Hartig, 
Book, Garvill, Olsson, and Garling 1996; Hartig, Evans, Jamner, Davis, and Gärling 2003; Hull 1992; Mayer et al. 2009), and emotional self-regulation (Korpela, Hartig, Kaiser, and Fuhrer 2001).

Insert Table 2 about here

\subsection{Restoration}

Visual, virtual or actual exposure to nature has been related to improvements in physiological responses (e.g. heart rate, blood pressure, muscle tension) (Agyemang et al. 2007; Miyazaki, Lee, Park, Tsunetsugu, and Matsunaga 2011; Ottosson and Grahn 2005; Park et al. 2010; Ulrich et al. 1991), attention capacity (Staats, Kiviet, and Hartig 2003), and affective states (McMahan and Estes 2015; Berto 2005; Hartig et al. 2003), following a stressful event (see Table 3). These effects are referred to as expressions of nature's restorative power (Ulrich 1979); their empirical investigation has started with the pioneering studies by Ulrich (1984) and Kaplan and Kaplan (1989). Ulrich (1984) has shown that patients who had a hospital room with a view of trees recovered more quickly and required fewer painkillers after a gallbladder surgery than patients with a view of a brick wall. Kaplan and Kaplan (1989) have demonstrated nature's ability of restoring mental capacity after prolonged fatigue in a series of studies. Subsequently, numerous studies have replicated these findings, with a body of research utilising various antecedent conditions (mental fatigue, stress, anxiety), assessed variables (physiological, affective or cognitive measures), and type of nature exposure. Positive participant response has been found both after spending time in nature (Hartig et al. 2003; Hartig, Mang, and Evans 1991), and after being exposed to real or virtual natural 
scenes ( McMahan and Estes 2015; Berto 2005; Hartig et al. 1996; Laumann, Gärling, and Stormark 2003; Parsons, Tassinary, Ulrich, Hebl, and Grossman-Alexander 1998; Ulrich et al. 1991; Van den Berg, Koole, and Van der Wulp 2003); and it should be noted that actual nature gives a stronger response than virtual nature (Kahn et al. 2008). With regard to the work and the workplace, Lee et al. (2015) found that a forty second view of green roof can restore attention, similarly Chow and Lau (2015) found that people exposed to photos of nature restored their 'inner-strength' after depletion to have greater persistence in logic and reasoning tasks. Lottrup, Grahn and Stigsdotter (2012) found a significant relationship between decreased stress and workplace attitude, and visual and physical access to workplace greenery. Such findings have informed workplace stress management interventions; for example Sahlin, Ahlborg, Matuszczyk and Grahn (2014) reduced long-term sick leave and stress symptoms through a garden and nature-based intervention.

Collectively, results from these studies have confirmed the greater physiological, cognitive and affective restorative power of natural settings. Physiological and affective recovery from viewing a stressful movie (Ulrich et al. 1991), and a video of a drive (Parsons et al. 1998) was faster in subjects who were exposed to natural, rather than urban, virtual scenes. Furthermore, exposure to nature stimuli has been shown to restore attention capacity (Hartig et al. 2003; Berman et al. 2008), to foster positive affect (Berto 2005), and to improve mood and concentration (Van den Berg, Koole, and van der Wulp 2003). For instance, a view of nature (Hartig et al. 2003), and the presence of plants in the workplace (Lohr, PearsonMims, and Goodwin 1996) have been associated with a more rapid decline in blood pressure after attention demanding tasks, leading to improved worker productivity.

Insert Table 3 about here 


\section{Connectedness with Nature}

Parallel to research investigating the benefits of being exposed to nature above, several recent studies have started to demonstrate the beneficial effects of nature connectedness (NC) (Mayer and Frantz 2004; Mayer, Frantz, Bruehlman-Senecal, and Dolliver 2009), although the importance of being connected to nature and the involved mechanisms are still unclear (Mayer et al. 2009). Rather than being a connection across some form of artificial humannature boundary, connectedness to nature is comprised of affective and experiential sense of belonging to the natural world (Mayer and Frantz 2004), and includes the extent to which nature is included within an individual's view of self (Schultz 2002). Individual differences are also important in possessing a connection to nature and involve the affective and experiential factors mentioned previously along with cognitive aspects (Zelenski and Nisbet 2014). Given the evidence presented above on exposure to nature, it would seem likely the level of connectedness to nature is important to health and well-being, and is therefore a potential route to improved health in the workplace.

\subsection{The Benefits of Nature Connectedness}

While the studies introduced earlier have focused on the association between exposure to nature and well-being, an emerging body of literature, see Table 4, has found a relationship between positive affect and individual differences in connectedness with nature (Cervinka et al. 2012; Howell, Dopko, Passmore, and Buro 2011; Nisbet et al. 2011). In particular, a connection to nature has been shown to significantly correlate with life satisfaction (Mayer and Frantz 2004), lower cognitive anxiety (Martyn and Brymer 2014), vitality (Cervinka et al. 2012), meaningfulness (Cervinka et al. 2012; Howell, Passmore, and Buro 2012; Mayer et al. 2009), happiness (Nisbet et al. 2011), and mindfulness (Howell et al. 2011). These correlations are of a similar magnitude to those found between well-being and other variables, 
such as marriage and education, whose relationships with well-being are well established (Mayer and Frantz 2004). Further, in a recent meta-analysis, Capaldi, Dopko and Zelenski (2014) found people with a stronger connection to nature experienced more life satisfaction, positive affect and vitality at levels associated with established predictors such as personal income. There is also emerging evidence of physiological responses to a more embedded experience of nature (e.g. Park et al. 2010).

Insert Table 4 about here

A recent campaign that encouraged daily nature contact for one month delivered sustained increases in health and happiness, with improvements in connection to nature mediating that relationship (Author, under review A). A connection to nature has also been demonstrated to partially mediate the relationship between exposure to nature and well-being; people who are more connected with nature, experience greater psychological benefits from contact with nature (Hartig, et al. 2011). More recently, the aspects that mediate the relationship between nature connectedness and well-being have been investigated, with spirituality (Kamitsis and Francis 2013) and natural beauty (Zhang, Howell and Iyer 2014) mediating the relationship between nature connection and psychological well-being. Thus, increasing people's connection to nature is at least as important as increasing the availability and access of green space, particularly in urban locations (Lin et al. 2014). While the emerging benefits of nature connectedness are important there is a need for further understanding of how to facilitate and improve people's connection to nature, and how this might translate to a workplace context. Further, there is a need to understand the pathways by 
which people connect to nature, for example through contact, meaning, emotional attachment, compassion and nature's beauty (Author, Under Review B). The benefits and routes to nature connection outlined above are summarised in Figure 1.

[Figure 1 near here]

\subsection{Nature-Human Relationship Theory}

Several theories have been developed to account for the human need for nature and the beneficial effects of nature. A brief insight of three key theories related to human-nature relationship is useful. Wilson's (1984) biophilia hypothesis is widely acknowledged and provides background and a catalyst for much research into human-nature relations (Hartig et al. 2011) and has informed the biophilic design of buildings (Kellert, Heerwagen and Mador 2011; Ryan et al. 2014), which has clear links to ergonomics (Thatcher 2013). Biophilia states that humans have an inborn tendency to affiliate with nature (Wilson 1984). This spontaneous affiliation with nature is justified from an evolutionary perspective as humans have lived for most of their existence embedded in natural environments (Frumkin 2001; Pretty 2002). Our cognitive and emotional apparatus instinctively respond with attraction or aversion to natural stimuli. Human innate affiliation with nature is therefore argued to be an indirect confirmation of its beneficial effects (Wilson 1984). Similarly, Ulrich's (1993) psycho-evolutionary model posits humans' innate affiliation with natural environments. In particular, Ulrich et al. (1991) argues that natural environments induce positive emotions and soothe autonomic arousal. This occurs because humans respond positively to natural environments, in which survival possibilities abound. Hence, natural environments elicit an 
affective and psycho-physiological restorative effect on humans (Ulrich 1993). Rather than focusing on nature's ability of restoring from stress, Kaplan and Kaplan's (1989) Attention Restoration Theory focuses on nature's role in recovering from mental fatigue, of particular relevance to ergonomics. According to Kaplan (2001), nature's main beneficial effect lies in the effortless attention and pleasurable fascination that natural settings elicit in humans. This provides them with a chance to restore their attention capacity and to recover from the mental fatigue caused by the cognitive tasks of modern society in which prolonged directed attention is required (Kaplan 1995).

From an ergonomics perspective, the cyberneticist Bateson (1972), and more recently Guddemi (2010), propose a systems-orientated approach to the relationship between individuals and nature. In this interpretation, consciousness, which is primarily goal-directed, is only a partial window on our systemic, dynamic relationship with our environment. A closer relationship with nature, which includes greater exposure to and immersion within nature, may facilitate a move away from a purely egocentric and goal-directed interpretation of the world and, allow us to develop a more holistic relationship with our environment in the broadest sense (Bateson 1972). One possibility is such a shift away from goal-driven activity may encourage an emphasis on right-hemisphere over left-hemisphere processing (Guddemi 2010). This shift in processing would also map to a shift between using local-feature processing, located in the left-hemisphere, and more global feature processing, located in the right-hemisphere (Fink et al. 1996), which could explain the restorative effects of nature after a demanding attentional task (Kaplan and Kaplan 1989; Staats, Kiviet, and Hartig 2003).

\section{Research into the Beneficial Effects of Nature: Critical Analysis}

The reviewed studies constitute a comprehensive and diverse body of research, demonstrating exposure to nature can: reduce hyper-tension, respiratory tract and cardiovascular illnesses; 
improve vitality and mood; benefit issues of mental wellbeing such as anxiety; and of particular note for workplace performance, restore attention capacity and mental fatigue. The research provides an evidence base for nature as a new paradigm for ergonomics and support for the ergonomist advocating provision and access to nature in order to improve health, wellbeing, restoration and ultimately absenteeism and productivity.

The literature presented is characterised by a variety of samples, designs (correlational, quasi-experimental, and empirical), and settings (laboratory and field). Nevertheless, it is not without methodological and conceptual limitations. The predominance of self-reported measures for the health and well-being assessments listed in Tables 1 and 2 is a weakness, as self-reported measures may lack objectivity and introduce reporting biases and artefacts (Braun, Woodley, Richardson, and Leidner 2012). However, physiological and non-selfreport measures (including performance measures such as attention which are of interest to ergonomists) do feature strongly in the studies on the restorative benefits in nature (see Table 3), and measures such as heart rate and blood pressure here are precursors and indicators of health and well-being. This research also tends to be empirical, covering both exposure to real and virtual nature, raising confidence in the self-report studies that dominate the health and well-being literature.

Although most of the health related studies in table 1 have large sample sizes, a correlational design is used in many of the studies looking to establish the relationship between nature, health and well-being. This approach is repeated by those studies investigating the well-being benefits of the emerging construct of nature connection summarised in table 4. However, these correlational studies do not allow for causal inferences. Now that the relationship between nature, health and well-being is well established investigating the mechanisms by which nature brings about health becomes paramount as this helps establish a cause-and-effect link (Kuo 2015). Whereas evidence of 
nature's positive effects abounds, few studies have attempted to examine the mechanisms underpinning this relationship (e.g. Van den Berg et al. 2010; Kuo 2015). Although several possible mediators have been identified (e.g. exercise promotion, social contact facilitation) (Brown and Bell 2007; Kuo 2001; Maas, Verheij, Spreeuwenberg, and Groenewegen 2008), only nature's restorative power has been extensively researched (Hartig et al. 2003; Ulrich et al. 1991). This lack of investigation into the underpinning mechanisms and moderating factors is frequent in the environmental and eco-psychology literature (Winkel, Saegert, and

Evans 2009). Because of the complex interactions among the environment, outcome variables, and other psychological and social factors, research designs are often simplified leading to the mechanisms involved to not be extensively investigated. Therefore, a challenge for ergonomists is to disambiguate the direct and indirect factors involved in the benefits brought about by human relationships with nature and consider how these relationships can be deepened within the workplace through both environmental design and behavioural interventions. Ergonomists are well-placed to take the holistic perspective required to progress this work, bringing together many disciplines and building on an understanding of the richness of the human-nature relationship revealed by a range of research approaches.

\section{Implications for Ergonomics}

\subsection{Applied Value}

The well-being benefits of nature are often overlooked in reviews and models of workplace well-being (e.g. Danna \& Griffin, 1999; Wilson et al. 2004) and in guidance on creating healthy workplaces (e.g. Day et al. 2014). Similarly, although workplace health promotion is known to be valuable for employee's well-being, the literature is limited beyond traditional approaches such as exercise (e.g. Kuoppala et al. 2008), despite nature exposure being an easy and inexpensive solution (Trau, Keenan, Goforth, and Large 2015). Likewise, 
key texts in ergonomics do not promote the benefits of the natural environment for well-being and restoration performance (e.g. Salvendy, 2012). Given the importance of the work environment and that stressors at work are associated with ill-health such as common mental disorders (e.g. Stansfeld et al. 2006), there is a need to promote the full-range of solutions. A nature-orientated approach is taken in urban design for public health (e.g. Brown \& Grant, 2005; Tzoulas et al, 2007) and the design of biophillic buildings (e.g. Ryan et al. 2014), but there is a need for nature-based solutions to become part of ergonomics practice. The strong evidence base for the benefits of nature, and lack of formal guidance, allows the ergonomist freedom to make nature part of the working day in the most straightforward and costeffective manner; with evaluation of outcomes where possible to build the research base.

For example, good work on the benefits of rest breaks on productivity and well-being (e.g. Dababneh et al. 2001) that has informed practice can be enhanced through those breaks including restorative natural environments. There has been a shift from manual to nonmanual work, and as the physical and chemical hazards have become more controlled, there has been a greater focus on the psychosocial environment at work, particularly the social environment and the key factors of psychological job demands and decision latitude (Kuoppala et al. 2008). These factors can be used to identify high strain jobs with greater risk of illnes, anxiety, depression and fatigue (Karasek \& Theorell, 1992). Just as social support can 'buffer' the impact of these demands (Johnson \& Hall, 1988), nature, as evidenced in the literature above, also provides restorative benefits. Recently, Sachita \& Ruchi (2015) have found that working in a restorative and green environment is a mediator of the relationship between organizational socialization and employee happiness. Clearly, the beneficial effects of nature can be included in current models, as a restorative buffer and mediator of workplace well-being. Access to nature at work may be as fundamental as the need for a rest break. 
The success of nature-based interventions will be influenced by the environmental context and also the workplace culture, for example are activities needed to encourage employees to simply spend some time outside each day. This has some interesting implications when considering the constraints that work design may place on the access to nature. One area where this is apparent is shiftwork. There is mounting evidence for the negative consequences of shiftwork (e.g. Vyas et al. 2012), which can be mediated by quite practical issues, for example, the lack of opportunities for good nutrition, and the need for increased caffeine intake (Amani and Gill 2013). For many shift workers, there will be limited or no access to nature during rest periods simply because it is dark and nearby parks, or the areas surrounding the parks may be unsafe (Bedimo-Rung et al. 2005). If nature is to be implemented within worker well-being, strategies will also need to consider access for shift and night workers.

In addition to supporting a nature as a new paradigm for ergonomics and workplace well-being, the literature on nature's beneficial effects has great applied value for leveraging the value of the natural environment at work and informing practice, with recent examples demonstrating this well. In a correlational study, outdoor, indoor and indirect contact with nature within the workplace was positively related to decreases in stress and related health issues, suggesting contact with nature contributes to a healthy work environment (LargoWight, Chen, Dodd and Weiler 2011). From an intervention perspective, Sahlin et al. (2014) used nature and gardening activities within a multimodal stress management course. The 12week course involving gardening and nature walks led to reductions in burnout, long-term sick leave and improved work ability over a 12 month follow-up. Similarly, Tyrväinen et al. (2014) showed that short-term visits to a large urban park during the working day reduced both perceived stress and cortisol levels, while Brown, Barton, Pretty and Gladwell (2014) found a nature based 'Walks4Work' intervention to be more effective than a built 
environment walk in improving mental health. Although there is evidence of the benefits of a connection to nature, there is little work on how to improve connection to nature in a sustained manner. From the work presented above, suggestions include noting the good things in nature, such as nature's beauty, though writing or activities such as photography which can give walks from work a purpose. However, the literature is yet to provide a clear set of guidelines for the best nature-based pathways for workplace wellbeing.

Despite the lack of clear guidance, the breadth of research considered above shows that a great deal of benefit can come in three areas. Simple exposure to nature in the form of green spaces, gardens and trees, and even plants in the office. There was evidence that simply having a view of such spaces is beneficial, with windowless workers more likely to want plants and pictures of nature (Bringslimark, Hartig and Grindal Patil 2011). Once access to nature is established, informal measures can be taken to encourage employees to spend time in nature, both during breaks and as a location for meetings as part of health promotion campaigns. Secondly, and more specifically, given the research on restoration, time in nature can be formalised, particularly for those jobs that place high demands on attention. Thirdly, formal nature-based interventions can be designed to deliver benefits such as reductions in burnout and sick leave.

Finally, as discipline ergonomics should engage with global challenges where it can, such as sustainability, climate change and the state of nature (e.g. Moray, 1993; Thatcher, 2013). Strengthening human exposure to, and connection with nature through simple interventions would be not only beneficial for human health and well-being, but for the environment as well, and there is a need for a coalition of disciplines to promote human interaction with nature (Sandifer et al. 2014). Literature has shown that, in contrast with negative, alarmist campaigns which can make us feel helpless (PIRC 2013), connectedness with nature (Mayer and Frantz 2004), and exposure to nature (Brown and Kasser 2005; Ewert, 
Place, and Sibthorp 2005; Hartig, Kaiser, and Bowler 2001) encourage environmentally friendly attitudes and behaviours. It would be anticipated that considerations relevant to other forms of successful health and safety intervention, such as energy and creativity, engagement and so on (Hale et al. 2010) will be as relevant to interventions to bring nature into working practice.

\subsection{Further Implications}

The wellbeing benefits of nature provide one aspect of a new paradigm for ergonomics in the delivery of wellbeing. There are, however, wider implications for the discipline related to the reasons nature is beneficial, and our shared place in nature. Connectedness to nature was introduced earlier as a sense of belonging to the natural world (Mayer and Frantz 2004) which includes the extent to which nature is included within an individual's view of self (Schultz 2002). The self is a key construct in Western thinking and the disembodied or independent self is a common notion in modern Western societies (Bragg 1996). This philosophical stance is built upon the dominant Cartesian tradition of modernity where the object is seen as separate from the subject. An alternative is a phenomenological perspective (e.g. Merleau-Ponty and Lefort 1968) which suggests a shared place in the world.

There has been previous discussion of phenomenology and ergonomics, for example a phenomenology of human-machine interaction, or coagency, where the machine becomes 'transparent' and part of how the world is experienced (Hollnagel and Woods 2005). The roots of such cognitive integration, where mind and environment operate as a coupled system (Clark and Chalmers 1998; Thompson 2010), can be found in phenomenology and the philosophy of Merleau-Ponty (e.g. Merleau-Ponty and Lefort 1968); thinking that has developed into embodied cognition (e.g. Clark 1997; Gallagher 2005; Lakoff and Johnson 1999) and the notion of the extended mind. Concepts such as distributed and extended cognition, discussed previously in the ergonomics literature (e.g. Hollnagel 2001) are also 
relevant. These perspectives suggest that the mind extends beyond the body to be embedded in the environment, so, for example, that hand tools become integrated by the mind into body schema and the task becomes deeply integrated into our experience (e.g. Borghi and Cimatti 2010).

Ergonomics, at its core, is interested in the relationship between the environment and people, although this is often from a positivist perspective (Dekker, Hancock and Wilkin 2013) involving some 'interface' which suggests a boundary where the task is an external element, something we encounter. However, from nature connection, to cognitive integration, embeddedness and well-being there is value, in a more general integrative perspective as it is difficult to establish where the environment begins and system ends (Dekker et al. 2013). Building upon the concept of connection to nature where self and the external natural world are integrated, the task becomes part of our being. Being is our interaction with the world and the things we do within it, so that fitting the task to the human, goes beyond interaction to our situated state, place and cognition. The philosophical basis underpinning nature connectedness, self, and embeddedness provides a different, and fully holistic, perspective for ergonomics - if people are embedded within the natural environment, they are also embedded within the work environment. This viewpoint is represented in figure 2 , where the straightforward 'concentric rings' model of ergonomics which depicts interactions of factors relevant to applied ergonomics is adapted (Grey, Norris and Wilson 1987; Wilson and Corlett 2005). The adaptation attempts to capture the holistic need to consider nature within the workplace through the encompassing leaf, but the model also references the phenomenological perspective of nature connectedness, task embeddedness and cogntive integration through the larger central figure which shares experiences with all factors directly, rather than across a series of boundaries, therefore providing a straightforward focal point to inform education and scholarship in the epistemology of ergonomics (Dekker, Hancock and 
Wilkin 2013); the second of the two objects of chartership being to advance education and knowledge in ergonomics (CIEHF 2014). As noted earlier, a move away from a positivist, goal-directed interpretation of the world to a holistic perspective, may itself be facilitated by a closer relationship with nature (Bateson 1972).

[Figure 2 near here]

More generally, this embeddedness within the environment provides a new paradigm for well-being. Stevens (2010) presents an ecopsychological view in contrast to existing models of health which essentially view people as separate from the environment and affected by specific events. The 'biomedical' model of medicine is based on a deviation from 'normal' within the individual, with the 'biopsychosocial' model reflecting how biological, psychological and social factors play a significant role in health (Engel 1977). Seeing people as embedded within the environment shifts the emphasis away from the person and their health issues to a consideration of dynamic relationships between people and environment. Given the evidence above, it is time for a wider paradigm shift and an embedded model based on 'biopsychophysis', reflecting how health depends on the unity of biology, psychology and nature.

In summary, the concept of nature connectedness is further argument for a paradigm shift in ergonomics, with a move away from purely reductive Cartesian viewpoints (e.g. Dekker, Hancock and Wilkin 2013), echoing debate on other core topics for ergonomics such as situation awareness (e.g. Dekker 2013; Stanton et al. 2014) whereby the role of the individual, and their understanding of their environment, is indivisible from the environment 
as a unit of analysis.

\section{Future Research}

Although the evidence of nature's benefits to health and well-being is extensive, more work is required on the linkages between biodiversity, nature and health. In order to place nature at the centre of human well-being there is a need for research on mechanisms and quantification of wellbeing outcomes to drive policy change (Sandifer et al. 2014). From an applied perspective, at present, the knowledge about the beneficial effects of nature, and the most beneficial kinds of interaction with nature, are insufficient to be applied in a systematic way in areas related to health promotion (Van den Berg et al. 2007). Future research should therefore focus on applied studies aimed at exploring ways to translate theoretical notions, such as nature as a restorative environment, into practice and to assess the effectiveness of nature-based interventions in the workplace to inform policy and well-being programmes.

To expand, this research should follow the three themes set out in the applied implications for ergonomics above. Firstly, how does exposure to, and time in, nature impact on employee health, well-being and performance? The research for this broader question is likely to take a cross-sectional and self-report approach, particularly in the first instance before building into intervention based studies that will also support a causal link. Secondly, informed by wider research into theoretical knowledge of mechanisms, there is a need to tackle applied issues head-on and explore nature interventions as a route to well-being (c.f. Author, Under Review B). Such studies would consider the design and evaluation of formal nature-based interventions to deliver benefits such as reductions in burnout, sick leave and improved performance. Such work should do more to empirically examine the value of nature as distinct from other associated factors that might lead to well-being benefits such as exercise or greater exposure to daylight (Mills et al. 2007). As with the research presented 
earlier, depending on the outcome being targeted, both subjective and objective measures are possible. Research in the first two themes should also consider associated benefits such as people's connection to nature and pro-environmental behaviours. Thirdly, there is an opportunity for research into how time in nature can be formalised and implemented as a restorative break based intervention, particularly for those jobs that place high demands on attention. Building on the laboratory and empirical research into restoration and attention, this research should be field based with applied performance measures. Finally, these broad research themes would inform the revision of models of workplace well-being to include nature. This process of moving from theory to concrete guidance is presented in figure 3 .

[Figure 3 near here]

\section{Conclusions}

Although there is work to be done to understand the relationship further, the message for the practitioner is straightforward: exposure to nature is beneficial to wellbeing. There is freedom to bring nature into the work environment in numerous ways, and the opportunity to cement a paradigm shift by evaluating and reporting the impact. As humans are part of nature, there can be no surprise that exposure to nature is beneficial for our well-being. While modern life is preferable to that of our predecessors in many ways, it has created new pressures and recently, health experts have started to recognise that a divorce from nature may present high costs, not just in terms of health but also in wider concerns about disrupting the systemic relationship between us and our environment (Bateson 1972; Guddemi 2010). A large body of literature has demonstrated that nature exerts many beneficial effects on humans. People 
who are exposed to nature, or feel connected with it, seek out natural places in urban locations and present higher levels of well-being, as nature has been shown to have a restorative effect on both a stressed autonomic nervous system and a depleted attention capacity. Extending and sharing this knowledge has importance in behavioural and work environment interventions in which nature's beneficial effects could be capitalised and a positive attitude towards nature can be encouraged as we work towards a sustainable future. For ergonomics, this presents a new paradigm for its object of promoting human well-being, knowledge that should be incorporated to meet the second of the two objects of chartership, to advance education and knowledge in ergonomics (CIEHF 2014). As nature-based solutions come to the fore, ergonomists should understand the value of nature, and how to accommodate its impact within working environments and working patterns. Moreover, the systemic relationship between us and nature further highlights the relevance of a nondualistic stance between people and the environment that is applicable to all aspects of ergonomics and socio-technical approaches.

\section{References}

Agyemang, C., van Hooijdonk, C., Wendel-Vos, W., Ujcic-Voortman, J., Lindeman, E., Stronks, K., and Droomers, M. 2007. "Ethnic Differences in the Effect of Environmental Stressors on Blood Pressure and Hypertension in the Netherlands." Biomedcentral Public Health 7 (1): 118. doi: 10.1186/1471-2458-7-118

Amani, R., and Gill, T. 2013. "Shiftworking, Nutrition and Obesity: Implications for Workforce Health-A Systematic Review." Asia Pacific journal of clinical nutrition 22 (4): 505 .

Author. 2013. [details removed for peer review]. Author. 2015. [details removed for peer review]. 
Author (under review A). [details removed for peer review].

Author (under review B). [details removed for peer review].

Bandura, A. 2007. "Impeding Ecological Sustainability Through Selective Moral

Disengagement." International Journal of Innovation and Sustainable Development 2

(1): 8-35. doi: 10.1504/IJISD.2007.016056

Barnosky, A. D., Matzke, N., Tomiya, S., Wogan, G. O. U., Swartz, B., Quental, T. B., Marshall, C., McGuire, J. L., Lindsey, E. L., Maguire, K. C., Mersey. B., and Ferrer, E. A. 2011. "Has the Earth's Sixth Mass Extinction Already Arrived?" Nature 471, 51-57. doi:10.1038/nature09678

Bateson, G. 1972. "Effects of Conscious Purpose on Human Adaptation." Steps to an Ecology of Mind 440-447.

Berman, M. G., Jonides, J., \& Kaplan, S. 2008. "The cognitive benefits of interacting with nature.” Psychological science 19 (12): 1207-1212.

Berto, R. 2005. "Exposure to Restorative Environments Helps Restore Attentional Capacity." Journal of Environmental Psychology 25 (3): 249-259. doi:

10.1016/j.jenvp.2005.07.001

Borghi, A. M., and F. Cimatti. 2010. "Embodied Cognition and Beyond: Acting and Sensing the Body." Neuropsychologia 48: 763-773. doi:10.1016/j.neuropsychologia.2009.10.029

Bragg, E. A. 1996. "Towards Ecological Self: Deep Ecology Meets Constructionist Self Theory." Journal of Environmental Psychology 16: 93-108.

Braun, E., Woodley, A., Richardson, J. T. E., and Leidner, B. 2012. "Self-rated Competences Questionnaires from a Design Perspective." Educational Research Review 7 (1): 1-18. 
Bringslimark, T., Hartig, T., and Grindal Patil, G. 2011. "Adaptation to Windowlessness: Do Office Workers Compensate for a Lack of Visual Access to the Outdoors?" Environment and Behaviour 43 (4): 469-487. doi: 10.1177/0013916510368351

Brown, D. K., Barton, J. L., Pretty, J. N., \& Gladwell, V. 2014. "Walks4Work: Assessing the role of the natural environment in a workplace physical activity intervention." Scandinavian Journal of Work, Environment \& Health 40 (4): 390-399. doi: $10.5271 /$ sjweh. 3421

Brown, C., \& Grant, M. 2005. "Biodiversity and human health: What role for nature in healthy urban planning?" Built Environment 31 (4): 326-338.

Brown, K. W., and Kasser, T. 2005. "Are Psychological and Ecological Well-being Cmpatible? The Role of Values, Mindfulness and Life Style." Social Indicators Research 74 (2): 349-368. doi: 10.1007/s11205-004-8207-8

Brown, T., and Bell, M. 2007. "Off the Couch and on the Move: Global Public Health and the Medicalisation of Nature." Social Science and Medicine 64 (6): 1343-1354. doi: 10.1016/j.socscimed.2006.11.020

Burns, G. W. 2005. "Naturally Happy, Naturally Healthy: The Role of the Natural Environment in Well-being." In The Science of Well-being, edited by F. A. Huppert, N. Baylis, and B. Keverne, 405-431. Oxford: Oxford University Press.

Buzzell, L., and Chalquist, C. 2009. Ecotherapy: Healing with Nature in Mind. San Francisco, CA: Sierra Club.

Capaldi, C. A., Dopko, R. L., \& Zelenski, J. M. 2014. "The relationship between nature connectedness and happiness: a meta-analysis." Frontiers in psychology 5.

Cervinka, R., Röderer, K., and Hefler, E. 2012. "Are Nature Lovers Happy? On Various Indicators of Well-being and Connectedness with Nature." Journal of Health Psychology 17 (3): 379-388. doi: 10.1177/1359105311416873 
Chartered Institute of Ergonomics and Human Factors. 2014. Royal Charter. http://iehf.org/ehf/wp-content/uploads/2013/04/CIEHF-Charter-documents.pdf

Chow, J. T., and Lau, S. 2015. "Nature Gives Us Strength: Exposure to Nature Counteracts Ego-depletion." The Journal of Social Psychology 155 (1): 70-85.

Cimprich, B., and Ronis, D. L. 2003. "An Environmental Intervention to Restore Attention in Women with Newly Diagnosed Breast Cancer." Cancer Nursing 26 (4): 284-292.

Clark, A. 1997. Being there. MIT Press, Cambridge MA.

Clark, A., and Chalmers, D. 1998. "The Extended Mind." Analysis 58, 7-19.

Dababneh, A. J., Swanson, N., \& Shell, R. L. 2001. "Impact of added rest breaks on the productivity and well being of workers.” Ergonomics 44 (2): 164-174.

Dadvand, P., de Nazelle, A., Figueras, F., Basagaña, X., Sue, J., Amoly, E., Jerrett, M., Vrijheid, M., Sunyer, J., and Nieuwenhuijsen, M. J. 2012. Green Space, Health Inequality and Pregnancy. Environent International 40: 110-115.

Danna, K., \& Griffin, R. W. 1999. "Health and well-being in the workplace: A review and synthesis of the literature." Journal of management 25 (3): 357-384.

David Suzuki Foundation 2015. 30x30 Nature Challenge. http://30x30.davidsuzuki.org Day, A., Kelloway, E. K., \& Hurrell Jr, J. J. (Eds.). 2014. Workplace Well-being: How to Build Psychologically Healthy Workplaces. John Wiley \& Sons.

Dekker, S. W. 2013. "On the Epistemology and Ethics of Communicating a Cartesian Consciousness." Safety Science 56: 96-99

Dekker, S. W., Hancock, P. A., and Wilkin, P. 2013. "Ergonomics and Sustainability: Towards an Embrace of Complexity and Emergence." Ergonomics 56 (3): 357-364. Department for Environment, Food and Rural Affairs. 2011. The Natural Choice: Securing the Value of Nature (Vol. 8082). The Stationery Office. 
de Vries, S., Verheji, R., Groenewegen, P., and Spreeuwenberg, P. 2003. "Natural Environments - Healthy Environments? An Exploratory Analysis of the Relationship Between Greenspace and Health." Environment and Planning 35 (10): 1717-1731.

Donovan, G. H., Butry, D. T., Michael, Y. L., Prestemon, J. P., Liebhold, A.M., Gatziolis, D., and Mao, M.Y. 2013. "The Relationship Between Trees and Human Health: Evidence from the Spread of the Emerald Ash Borer." American Journal of Preventive Medicine 44 (2): 139-145. doi: 10.1016/j.amepre.2012.09.066

Dunn, R. R., Gavin, M. C., Sanchez, M. C., and Solomon, J. N. 2006. "The Pigeon Paradox: Dependence of Global Conservation on Urban Nature." Conservation Biology 20 (6): 1814-1816.

European Commission. 2015. Towards an EU Research and Innovation policy agenda for Nature-Based Solutions \& Re-Naturing Cities: Final Report of the Horizon 2020 Expert Group on 'Nature-Based Solutions and Re-Naturing Cities' https://ec.europa.eu/research/environment/pdf/renaturing/nbs.pdf

European Environment Agency. 2015. State of nature in the EU. http://www.eea.europa.eu/publications/state-of-nature-in-the-eu/at_download/file Engel, G. L. 1977. "The Need for a New Medical Model: a Challenge for Biomedicine." Science 196 (4286): 129-136.

Ewert, A., Place, G., and Sibthorp, J. 2005. "Early-life Outdoor Experiences and an Individual's Environmental Attitudes." Leisure Sciences 27 (3): 225-239.

Flach, J. M., Dekker, S., \& Jan Stappers, P. (2008). Playing twenty questions with nature (the surprise version): Reflections on the dynamics of experience. Theoretical Issues in Ergonomics Science, 9(2), 125-154.

Frantz, C. M. and Mayer, F. S. 2014. "The Importance of Connection to Nature in Assessing Environmental Education Programs." Studies in Educational Evaluation 41: 85-89. 
Frumkin, H. 2001. "Beyond Toxicity: Human Health and the Natural Environment." American Journal of Preventive Medicine 20 (3): 234-240. doi: 10.1016/S07493797(00)00317-2

Gallagher, S. 2005. How the Body Shapes the Mind. Oxford University Press, Oxford.

Gidlof-Gunnarsson, A., and Ohrstrom, E. 2007. "Noise and Well-Being in Urban Residential Environments: The Potential Role of Perceived Availability to Nearby Green Areas." Landscape and Urban Planning 83 (2): 115-126. doi:

10.1016/j.landurbplan.2007.03.003

Grey, S.M., Norris, B.J. and Wilson, J.R. 1987. Ergonomics in the Electronic Retail Environment. Slough: ICL (UK).

Groenewegen, P., van den Berg, A., de Vries, S., and Verheij, R. 2006. "Vitamin G: Effects of Green Space on Health, Well-being, and Social Safety." BMC Public Health 6 (1): 149. doi: 10.1186/1471-2458-6-149

Guddemi, P. 2011. "Conscious Purpose in 2010: Bateson's Prescient Warning." Systems Research and Behavioral Science 28 (5): 465-475.

Guite, H. F., Clark, C., and Ackrill, G. 2006. "The Impact of the Physical and Urban Environment on Mental Well-being." Public Health Nutrition 120 (12): 1117-1126. doi: 10.1016/j.puhe.2006.10.005

Gullone, E. 2000. "The Biophilia Hypothesis and Life in the 21st Century: Increasing Mental Health or Increasing Pathology?" Journal of Happiness Studies 1 (3): 293-322. doi: 10.1023/A:1010043827986

Hale, A. R., Guldenmund, F. W., Van Loenhout, P. L. C. H., and Oh, J. I. H. 2010. Evaluating Safety Management and Culture Interventions to Improve Safety: Effective Intervention Strategies. Safety Science 48 (8): 1026-1035. 
Hanson, M. A. 2013. "Green ergonomics: challenges and opportunities." Ergonomics 56 (3): $399-408$.

Hartig, T., Book, A., Garvill, J., Olsson, T., and Garling, T. 1996. "Environmental influences on psychological restoration." Scandinavian Journal of Psychology 37 (4): 378-393. doi: 10.1111/j.1467-9450.1996.tb00670.x

Hartig, T., Evans, G. W., Jamner, L. D., Davis, D. S., and Gärling, T. 2003. "Tracking restoration in natural and urban field settings." Journal of Environmental Psychology 23 (2): 109-123. doi: 10.1177/0013916508319745

Hartig, T., Kaiser, F. G., and Bowler, P. A. 2001. "Psychological Restoration in Nature as a Positive Motivation for Ecological Behavior." Environment and Behavior 33 (4): 590607. doi: 10.1177/00139160121973142

Hartig, T., Mang, M., and Evans, G. W. 1991. "Restorative Effects of Natural Environment Experiences." Environment and Behavior 23(1): 3-26. doi: $10.1177 / 0013916591231001$

Hartig, T., van den Berg, A., Hägerhäll, C., Tomalak, M., Bauer, N., Hansmann, R., Ojala, A., Syngollitou, E., Carrus, G., van Herzele, A., Bell, S., Camilleri Podesta, M. T., and Waaseth, G. 2011. "Health Benefits of Nature Experience: Psychological, Social and Cultural Processes." In Forests, Trees, and Human Health, edited by Nilsson, K., Sangster, M., Gallis, C., Hartig, T., De Vries, S., Seeland, K., and Schipperijn, J., 127168. Dordrecht: Springer. doi:10.1007/978-90-481-9806-1

Health Council of the Netherlands. 2004. "Nature and Health. The influence of nature on social, psychological and physical well-being." http://www.gr.nl/sites/default/files/Nature_and_health.pdf

Hillsdon, M., Panter, J., Foster, C., and Jones, A. 2006. "The Relationship Between Access and Quality of Urban Green Space with Population Physical Activity." Journal of the 
Royal Institute of Public Health 120 (12): 1127-1132. doi:

10.1016/j.puhe.2006.10.007

Hollnagel, E. 2001. Extended Cognition and the Future of Ergonomics. Theoretical Issues in Ergonomics Science 2 (3): 309-315.

Hollnagel, E., and Woods, D. D. 2005. "Joint Cognitive Systems: Foundations of Cognitive Systems Engineering." CRC Press.

Howell, A., Passmore, H. A., and Buro, K. 2012. "Meaning in Nature: Meaning in Life as a Mediator of the Relationship Between Nature Connectedness and Well-Being." Journal of Happiness Studies 11 (1): 1-16. doi: 10.1007/s10902-012-9403-X

Howell, A. J., Dopko, R. L., Passmore, H. A., and Buro, K. 2011. "NatureConnectedness: Associations with Well-being and Mindfulness." Personality and Individual Differences 51 (2): 166-171. doi: 10.1016/j.paid.2011.03.037

Hull, R. B. I. 1992. "Brief Encounters with Urban Forests Produce Moods that Matter." Journal of Arboriculture 18 (6): 322-324.

Johansson, S. E., and Sundquist, J. 1999. "Change In Lifestyle Factors and their Influence on Health Status and All-Cause Mortality." International Journal of Epidemiology 28 (6): 1073-1080.

Johnson, J. V., \& Hall, E. M. 1988. “Job strain, work place social support, and cardiovascular disease: a cross-sectional study of a random sample of the Swedish working population.” American Journal of Public Health 78 (10): 1336-1342.

Kaczynski, A. T., and Henderson, K. A. 2007. "Environmental Correlates of Physical Activity: a Review of Evidence about Parks and Recreation." Leisure Sciences 29 (4): 315-354. doi: 10.1080/01490400701394865

Kahn, P. H., Friedman, B., Gill, B., Hagman, J., Severson, R. L., Freier, N. G., Feldman, N., Carrere, S. and Stolyar, A. 2008. "A Plasma Display Window?-The Shifting 
Baseline Problem in a Technologically Mediated Natural World." Journal of Environmental Psychology 28 (2): 192-199.

Kamitsis, I., and Francis, A.J.P. 2013. "Spirituality Mediates the Relationship Between Engagement with Nature and Psychological Wellbeing." Journal of Environmental Psychology 36: 136-143. doi: 10.1016/j.jenvp.2013.07.013.

Kaplan, R. 2001. "The Nature of the View from Home: Psychological Benefits." Environment and Behaviour 33 (4): 507-542. doi: 10.1177/00139160121973115

Kaplan, R., and Kaplan, S. 1989. The Experience of Nature. A Psychological Perspective. Cambridge: Cambridge University Press.

Kaplan, S. 1995. "The Restorative Benefits of Nature: Toward An Integrative Framework." Journal of Environmental Psychology 15 (3): 169-182.

Karasek, R., \& Theorell, T. 1992. Healthy work: stress, productivity, and the reconstruction of working life. Basic books.

Kellert, S. R., Heerwagen, J., and Mador, M. 2011. Biophilic design: the theory, science and practice of bringing buildings to life. John Wiley and Sons.

Korpela, K. M., Hartig, T., Kaiser, F. G., and Fuhrer, U. 2001. Restorative Experience and Self-Regulation in Favorite Places. Environment and Behaviour 33 (4): 572-589. doi: $10.1177 / 00139160121973133$

Kuo, F. E. 2001. "Coping With Poverty: Impacts of Environment and Attention in the Inner City." Environment and Behaviour 33 (1): 5-34. doi: 10.1177/00139160121972846

Kuo, M. 2015. "How might contact with nature promote human health? Promising mechanisms and a possible central pathway." Frontiers in Psychology 6. doi: 10.3389/fpsyg.2015.01093 
Kuoppala, J., Lamminpää, A., \& Husman, P. 2008. "Work health promotion, job well-being, and sickness absences - a systematic review and meta-analysis." Journal of Occupational and Environmental Medicine 50 (11): 1216-1227.

Lafortezza, R., Carrus, G., Sanesi, G., and Davies, C. 2009. "Benefits and Well-Being Perceived by People Visiting Green Spaces in Periods of Heat Stress." Urban Forestry and Urban Greening 8 (2): 97-108. doi: 10.1016/j.ufug.2009.02.003

Lakoff, G. and M. Johnson. 1999. Philosophy in the flesh: The Embodied Mind and its Challenge to Western Thought. New York: Basic Books.

Largo-Wright, E., Chen, W. W., Dodd, V. and Weiler, R. 2011. "Healthy Workplaces: The Effects of Nature Contact at Work on Employee Stress and Health." Public Health Report 1 (126): 124-130.

Leather, P., Pyrgas, M., Beale, D., and Lawrence, C. 1998. "Windows in the Workplace: Sunlight, View, and Occupational Stress." Environment and Behavior 30: 739-762. Laumann, K., Gärling, T., and Stormark, K. M. 2003. "Selective Attention and Heart Rate Responses to Natural and Urban Environments." Journal of Environmental Psychology 23 (2): 125-134.

Leopold, A. 1949. A Sand County Almanac: With Essays on Conservation from Round River. New York: Ballantine Books.

Lin, B.B., Fuller, R.A., Bush, R., Gaston, K.J. and, Shanahan, D.F. 2014. "Opportunity or Orientation? Who Uses Urban Parks and Why." PLoS ONE 9 (1). doi:10.1371/journal.pone.0087422

Logan, A. C., and Selhub, E. M. 2012. "Vis Medicatrix Naturae: Does Nature "Minister to the Mind"?" BioPsychoSocial Medicine 6 (1): 11-23. doi: 10.1186/1751-0759-6-11 
Lohr, V. I., Pearson-Mims, C. H., and Goodwin, G. K. 1996. Interior Plants may Improve Worker Productivity and Reduce Stress in a Windowless Environment. Journal of Environmental Horticulture 14 (2): 97-100.

Lottrup, L., Grahn, P., \& Stigsdotter, U. K. 2013. "Workplace greenery and perceived level of stress: Benefits of access to a green outdoor environment at the workplace." Landscape and Urban Planning 110: 5-11.

Louv, R. 2008. Last Child in the Woods: Saving our Children from Nature Deficit Disorder. Chapel Hill: Algonquin.

Luck, G.W., Davidson, P., Boxall, D., and Smallbone, L. 2011. "Relations Between Urban Bird and Plant Communities and Human Well-Being and Connection to Nature." Conservation Biology 25 (4): 816-826. doi: 10.1111/j.1523-1739.2011.01685.x

Maas, J., Verheij, R., Spreeuwenberg, P., and Groenewegen, P. 2008. "Physical Activity as a Possible Mechanism Behind The Relationship Between Green Space and Health: A Multilevel Analysis." BMC Public Health 8 (1): 206-219.

Maas, J., Verheij, R. A., Groenewegen, P. P., de Vries, S., and Spreeuwenberg, P. 2006. "Green Space, Urbanity, and Health: How Strong is the Relation?" Journal of Epidemiology and Community Health 60 (7): 587-592.

Maller, C., Townsend, M., St Leger, L., Henderson-Wilson, C., Pryor, A., Prosser, L., and Moore, M. 2009. "Healthy Parks, Healthy People: The Health Benefits of Contact with Nature in a Park Context." The George Wright Forum 26 (2): 51-83.

Martyn, P., and Brymer, E. 2014. "The relationship between nature relatedness and anxiety." Journal of Health Psychology 1359105314555169.

Mayer, F. S., Frantz, C. M., Bruehlman-Senecal, E., and Dolliver, K. 2009. "Why Is Nature Beneficial?: The Role of Connectedness to Nature." Environment and Behavior 41 (5): 607-643. 
Mayer, S. F., and Frantz, C. M. 2004. "The Connectedness to Nature Scale: A Measure of Individuals’ Feeling In Community with Nature." Journal of Environmental Psychology 24 (4): 503-515. doi: 10.1016/j.jenvp.2004.10.001

McMahan, E. A., and Estes, D. 2011. "Measuring Lay Conceptions of Well-being: The Beliefs about Well-Being Scale." Journal of Happiness Studies 12 (2): 267-287.

McMahan, E. A., and Estes, D. 2015. "The Effect of Contact with Natural Environments on Positive and Negative Affect: A Meta-Analysis." The Journal of Positive Psychology, (ahead-of-print): 1-13.

Mills, P. R., Tomkins, S. C., and Schlangen, L. J. 2007. "The Effect of High Correlated Colour Temperature Office Lighting on Employee Wellbeing and Work Performance." Journal of Circadian Rhythms 5 (1): 2.

Mitchell, R., and Popham, F. 2008. "Effect Of Exposure to Natural Environment on Health Inequalities: An Observational Population Study." Lancet 372 (9650): 1655-1660. doi: 10.1016/S0140-6736(08)61689-X.

Miyazaki, Y., Lee, J., Park, B. J., Tsunetsugu, Y., and Matsunaga, K. (2011). "Preventive Medical Effects of Nature Therapy". Japenese Journal of Hyiene 66 (4): 651-656. Moray , N. 1993. "Technosophy and humane factors." Ergonomics in Design, 1(4): 33-39. Newsham, G. R., Birt, B. J., Arsenault, C., Thompson, A. J., Veitch, J. A., Mancini, S., and Burns, G. J. 2013. "Do ‘Green’ Buildings Have Better Indoor Environments? New Evidence." Building Research \& Information 41 (4), 415-434.

Nisbet, E. K. and Zelenski, J.M. 2013. "The NR-6: A New Brief Measure of Nature Relatedness." Frontiers in Psychology 4 (813): 1-11. doi:10.3389/fpsyg.2013.00813

Nisbet, E., Zelenski, J., and Murphy, S. 2011. "Happiness is in our Nature: Exploring Nature Relatedness as a Contributor to Subjective Well-Being." Journal of Happiness Studies 12 (2): 303-322. doi: 10.1177/0956797611418527 
Nisbet, E. K., Zelenski, J. M., and Murphy, S. A. 2009. "The Nature Relatedness Scale: Linking Individuals' Connection With Nature to Environmental Concern and Behavior." Environment and Behavior, 41 (5): 715-740. doi:10.1177/0013916508318748

Ottosson, J., and Grahn, P. 2005. "A Comparison of Leisure Time Spent in a Garden with Leisure Time Spent Indoors: On Measures of Restoration in Residents in Geriatric Care." Landscape Research 30 (1): 23-55.

Ottosson, J., and Grahn, P. 2008. "The Role of Natural Settings in Crisis Rehabilitation: How Does ihe Level Of Crisis Influence the Response to Experiences of Nature with Regard to Measures of Rehabilitation?" Landscape Research 33 (1): 51-70. doi: $10.1080 / 01426390701773813$

Pappachan, M. J. 2011. "Increasing Prevalence of Lifestyle Diseases: High Time for Action." Indian Journal of Medical Research 134 (2): 143-145.

Park, B. J., Tsunetsugu, Y., Kasetani, T., Kagawa, T., and Miyazaki, Y. 2010. "The Physiological Effects of Shinrin-yoku (Taking in the Forest Atmosphere or Forest Bathing): Evidence from Field Experiments in 24 Forests Across Japan." Environmental Health and Preventive Medicine 15 (1): 18-26.

Parsons, R., Tassinary, L. G., Ulrich, R. S., Hebl, M. R., and Grossman-Alexander, M. 1998. "The View from the Road: Implications for Stress Recovery and Immunization." Journal of Environmental Psychology 18 (2): 113-140.

PIRC 2013. Common Cause for Nature - Full Report. http://valuesandframes.org/download/reports/Common\%20Cause\%20for\%20Nature\% 20-\%20Full\%20Report.pdf

Pretty, J. 2002. "Agri-culture: Reconnecting People, Land, and Nature." London: Earthscan. 
Pretty, J., Peacock, J., Hine, R., Sellens, M., South, N., and Griffin, M. 2007. Green Exercise in the UK Countryside: Effects on Well-being, and Implications for Policy and Planning. Journal of Environmental Planning and Management 50 (2): 211-231.

Raanaas, R. K., Patil, G. G., and Hartig, T. 2012. "Health Benefits of a View of Nature through the Window: A Quasi-experimental Study of Patients in a Residential Rehabilitation Center." Clinical Rehabilitation 26 (1): 21-32. doi: $10.1177 / 0269215511412800$

Roe, J., and Aspinall, P. 2011. The Restorative Benefits of Walking in Urban and Rural Settings in Adults with Good and Poor Mental Health. Health and Place 17 (1): 103 113. doi: 10.1016/j.healthplace.2010.09.003

Russell, R., Guerry, A. D., Balvanera, P., Gould, R. K., Basurto, X., Chan, K. M., and Tam, J. 2013. "Humans and Nature: How Knowing and Experiencing Nature Affect WellBeing." Annual Review of Environment and Resources 38: 473-502.

Ryan, C. O., Browning, W. D., Clancy, J. O., Andrews, S. L., and Kallianpurkar, N. B. 2014. "Biophilic Design Patterns: Emerging Nature-Based Parameters for Health and WellBeing in the Built Environment." International Journal of Architectural Research: ArchNet-IJAR 8 (2): 62-76.

Sachita, S. P., \& Ruchi, G. 2015. "Happiness and Organizational Socialization: Exploring the Mediating Role of Restorative Environments." International Research Journal of Social Sciences 4 (8): 15-20.

Sahlin, E., Ahlborg, G., Vega Matuszczyk, J. and Grahn, P. 2014. "Nature-Based Stress Management Course for Individuals at Risk of Adverse Health Effects from WorkRelated Stress_-Effects on Stress Related Symptoms, Workability and Sick Leave." International Journal of Environmental Research and Public Health 11 (6): 65866611. doi: 10.3390/ijerph110606586 
Salvendy, G. 2012. Handbook of human factors and ergonomics. John Wiley \& Sons.

Sandifer, P. A., Sutton-Grier, A. E., \& Ward, B. P. 2015. "Exploring connections among nature, biodiversity, ecosystem services, and human health and well-being: Opportunities to enhance health and biodiversity conservation." Ecosystem Services 12: 1-15.

Schultz, P. W. (2002). "Inclusion with Nature: Understanding the Psychology of Humannature Interactions." In The Psychology of Sustainable Development, edited by P. Schmuck and P. W. Schultz, 61-78. New York: Kluwer.

Song, C., Ikei, H., Lee, J., Park, B-J., Kagawa, T. and Miyazaki, Y. 2013. "Individual Differences in the Physiological Effects of Forest Therapy Based on Type A and Type B Behavior Patterns." Journal of Physiological Anthropology 32 (14). doi:10.1186/1880-6805-32-14

St Leger, L. 2003. "Health and Nature-New Challenges for Health Promotion." Health Promotion International 18 (3): 173-175. doi: 10.1093/heapro/dag012

Staats, H., Kiviet, A., and Hartig, T. 2003. "Where to Recover from Attentional Fatigue: An Expectancy-Value Analysis of Environmental Preference." Journal of Environmental Psychology 23 (2): 147-157.

Stansfeld, S., \& Candy, B. 2006. "Psychosocial work environment and mental health—a meta-analytic review." Scandinavian Journal of Work, Environment \& Health 443462.

Stevens, P. 2010. "Embedment in the Environment: A New Paradigm for Wellbeing?" Perspectives in Public Health 130 (6): 265-269.

Thatcher, A. 2013. "Green Ergonomics: Definition and Scope." Ergonomics 56 (3): 389-398. Thompson, E. 2010. Mind in life: Biology, phenomenology, and the sciences of mind. Cambridge: Harvard University Press. 
Trau, D., Keenan, K. A., Goforth, M., \& Large, V. 2015. "Nature Contacts Employee Wellness in Healthcare." HERD: Health Environments Research \& Design Journal, 1937586715613585.

Tyrväinen, L., Ojala, A., Korpela, K., Lanki, T., Tsunetsugu, Y., \& Kagawa, T. 2014. "The influence of urban green environments on stress relief measures: A field experiment." Journal of Environmental Psychology, 38 1-9.

Tzoulas, K., Korpela, K., Venn, S., Yli-Pelkonen, V., Kaźmierczak, A., Niemela, J., \& James, P. 2007. "Promoting ecosystem and human health in urban areas using green infrastructure: a literature review." Landscape and urban planning 81 (3): 167-178.

Ulrich, R. S. 1979. "Visual Landscapes and Psychological Well-being." Landscape Research 4 (1): 17-19.

Ulrich, R. S. 1984. "View Through a Window may Influence Recovery from Surgery." Science 224 (4647): 420-421.

Ulrich, R. S. 1993. Biophilia, Biophobia and Natural Landscapes. In The Biophilia Hypothesis, edited by S. R. Kellert and E. O. Wilson, 75-137). Washington DC: Island Press.

Ulrich, R. S., Simons, R. F., Losito, B. D., Fiorito, E., Miles, M. A., and Zelson, M. 1991. "Stress Recovery During Exposure to Natural and Urban Environments." Journal of Environmental Psychology 11 (3): 201-230.

Van den Berg, A. E., Hartig, T., and Staats, H. 2007. "Preference for Nature in Urbanized Societies: Stress, Restoration, and the Pursuit of Sustainability." Journal of Social Issues in Mental Health Nursing 63 (1): 79-96.

Van den Berg, A., Koole, S., and van der Wulp, N. 2003. "Environmental Preference and Restoration. How are they Related?" Journal of Environmental Psychology 23 (2): 135-146. 
Van den Berg, A. E., Maas, J., Verheij, R. A., and Groenewegen, P. P. 2010. "Green Space as a Buffer Between Stressful Life Events and Health." Social Science and Medicine 70 (8): 1203-1210.

Verheij, R. A., Maas, J., and Groenewegen, P. P. 2008. "Urban-Rural Health Differences and the Availability of Green Space." European Urban and Regional Studies 15 (4): 307316. doi: $10.1177 / 0969776408095107$

Verheij, R. A., van de Mheen, H. D., de Bakker, D. H., Groenewegen, P. P., and Mackenbach, J. P. 1998. "Urban-rural Variations in Health in The Netherlands: Does Selective Migration Play a Part?" Journal of Epidemiology and Community Health 52 (8): 487493.

von Hertzen, L., Beutler, B., Bienenstock, J., Blaser, M., Cani, P. D., Eriksson, J., and de Vos, W. M. 2015. "Helsinki Alert of Biodiversity and Health." Annals of medicine 0: 1-8.

Vyas, M. V., Garg, A. X., Iansavichus, A. V., Costella, J., Donner, A., Laugsand, L. E., and Hackam, D. G. 2012. "Shift Work and Vascular Events: Systematic Review and Meta-analysis." BMJ 345, e4800.

Walsh, R. 2011. "Lifestyle and Mental Health." American Psychologist 66 (7): 579-592. doi: $10.1037 / \mathrm{a} 0021769$

Weich, S., Twigg, L., and Lewis, G. 2006. "Rural/non-rural Differences in Rates of Common Mental Disorders." British Journal of Psychiatry 188 (1): 51-57. doi: 10.1192/bjp.bp.105.008714

Wild Network 2015. Project Wild Thing The Wild Network. http://http://projectwildthing.com/thewildnetwork

Wilson, E. O. 1984. Biophilia. Cambridge: Harvard University Press.

Wilson, M. G., Dejoy, D. M., Vandenberg, R. J., Richardson, H. A., \& McGrath, A. L. 2004. "Work characteristics and employee health and well-being: Test of a model of healthy 
work organization." Journal of Occupational and Organizational Psychology 77 (4): $565-588$.

Wilson, J. R., and Corlett, N., eds. 2005. Evaluation of human work. CRC Press.

Winkel, G., Saegert, S., and Evans, G. W. (2009). An ecological perspective on theory, methods, and analysis in environmental psychology: Advances and challenges. Journal of Environmental Psychology 29 (3): 318-328.

Zelenski, J. M., and Nisbet, E. K. 2014. "Happiness and Feeling Connected: The Distinct Role of Nature Relatedness." Environment and Behavior 46 (1):, 3-23.

Zhang, J.W., Howell, R.T., and Iyer, R. 2014. "Engagement with Natural Beauty Moderates the Positive Relation between Connectedness with Nature and Psychological WellBeing," Journal of Environmental Psychology 38: 55-63.

Zhang, J. W., Piff, P. K., Iyer, R., Koleva, S., and Keltner, D. 2014. "An Occasion for Unselfing: Beautiful Nature Leads to Prosociality." Journal of Environmental Psychology 37: 61-72. 